\title{
EL PROBLEMA DEL CUARTO CUERPO
}

\section{THE PROBLEM OF THE FOURTH BODY}

\author{
JAVIER DE LA HigUERA* \\ Universidad de Granada
}

Resumen: A partir de la ensoñación de Paul Valéry acerca del «problema de los tres cuerpos», en que se fantasea con la idea de un "cuarto cuerpo", misteriosa encarnación de una entidad inexistente, el presente artículo investiga cuál puede ser la naturaleza de ese "cuarto cuerpo». Para ello, se analiza la dimensión histórica del cuerpo a partir de algunas ideas de M. de Certeau, estudiando desde ese punto de vista la analogía entre el cuerpo y la lengua, y reflexionando sobre el estatus ontológico de esa historicidad corporal con referencia a M. Foucault y J.-L. Nancy, principalmente.

Palabras Clave: ontología del cuerpo, historicidad, ficción, objetos transicionales, utopía, metafísica.

Aвstract: Based on Paul Valéry's dream of the «three-body problem,» in which he fantasizes about a «fourth body,» a mysterious incarnation of a non-existent entity, this article investigates the possible nature of this «fourth body.» To this end, the historical dimension of the body is analyzed based on some of M. de Certeau's ideas, studying the analogy between body and language from this perspective, and reflecting on the ontological status of the historicity of the body, mainly with reference to M. Foucault and J.-L. Nancy.

KEY WORDs: ontology of the body, historicity, fiction, transitional objects, utopia, metaphysics.

Departamento de Filosofía II, Facultad de Filosofía y Letras (Edificio Psicología). Campus de Cartuja, s/n, 18071- Granada. E-mail: jdelahiguera@ugr.es 
Con el cuerpo quizás pasa lo que decía san Agustín que pasa con el tiempo: si nadie me pregunta qué es, lo sé, y si me preguntan, no lo sé ${ }^{1}$ El cuerpo parece ser algo conocido y cotidiano, aproblemático y, al mismo tiempo, es en algunos momentos algo desconcertante y enigmático. Parece estar lo más cerca posible de cada uno de nosotros y, al mismo tiempo, en una irreductible lejanía. Realidad tangible, inmanente y compacta pero también como exterior y extraña. Sin embargo, puede que en la actualidad el problema del cuerpo se haya hecho mayor: en un mundo donde no hay enigmas y los tabúes son un tabú (G. Anders), donde las lejanías, exterioridades y extrañezas son explicables y por tanto reducibles a lo conocido, la dificultad del cuerpo (del que ya lo sabemos casi todo por la ciencia) parece ser sólo instrumental o técnica, sólo el problema de cómo gestionar los cuerpos, o de cómo los cuerpos pueden ser, por fin liberados, los nuevos sujetos de la ansiada felicidad. Enorme problema, entonces, para nosotros, el del cuerpo, que se da por resuelto para no plantearse.

Y en el ámbito político, la magnitud de nuestro problema es patente. El cuerpo, objeto tradicionalmente codiciado, sometido y negado por el poder, era la inmanencia natural sometida a todas las trascendencias históricas (la teológica, la egológica, la andrológica, la etnológica, etc.) y negada por todas las utopías. En la situación actual, en que han sucumbido en una misma caída todas las realidades trascendentes y todas las utopías, pareciera que están sentadas definitivamente las bases para resolver el problema político sobre un cuerpo recuperado en su positividad, dato y sustrato último. Pero, ¿¿de dónde puede sacar ahora el cuerpo su potencia política transformadora?, ¿̇cómo podrán los cuerpos desalmados ser el alma nueva de la revuelta? Antes, sometidos por los poderes e instancias trascendentes, sujetos por ellas, al mismo tiempo eran los cuerpos los sujetos entusiastas de la rebeldía. Negados por las utopías de todo género, al mismo tiempo eran también lugar de una afirmación de lo que no existe.

Nuestro problema del cuerpo no es (no es sólo) el de su sometimiento y su negación. Es el problema de que se nos ha hecho invisible o inexistente aquello que lo somete y lo niega, hasta el punto de que vivimos en la creencia de que nada lo niega ya o de que él es simple afirmación o positividad. Nuestro problema se abre al constatar que lo invisible e inexistente no es para nosotros nada.

1 Confesiones, Libro XI: «quid est ergo tempus? si nemo ex me quaerat, scio; si quaerenti explicare velim, nescio». 
El cuerpo parece existir en la actualidad por primera vez quieto y reconciliado consigo mismo, instalado en su nuda realidad, como una cosa del mundo (a pesar de que hoy sea un hecho cotidiano ver el cuerpo constituido por innumerables prótesis, precisamente por ello quizás); cosa del mundo que es también la más importante para nosotros porque nos permite disfrutar de nuestra ilimitada libertad y ser dueños de nosotros mismos y propietarios universales, con tal de que en la batalla por el mundo, se expulsen de él todos los restos que quedan de las oscuras fuerzas de la negatividad. Quisiera aquí sólo apuntar en qué dirección se podría iniciar una revisión del cuerpo: cuerpo como inquietud y negatividad, cuerpo indócil a la realidad.

En 1943, Paul Valéry escribe unas enigmáticas «Reflexiones sencillas sobre el cuerpo», en las que después de hablar de «la sangre y nosotros» (mostrando que nuestra vida "se reduce a nada o casi nada" una vez que eliminamos todo lo que en ella es sustituible), plantea el "problema de los tres cuerpos». Veamos antes cuáles son éstos. Primero, mi cuerpo. En cada instante sentimos que nos pertenece o que le pertenecemos, aunque no es una cosa; es el objeto más importante del mundo porque el mundo mismo se refiere a él; aunque es la «sustancia de nuestra presencia», sin embargo es informe, está lleno de extrañezas y misterios, constante a la vez que variable, y ofrece sólo instantes. Segundo, el cuerpo que ven los otros, que tiene una forma, que es el objeto de la contemplación amorosa, y que envejece ante el espejo; cuerpo visto desde fuera, inclinado hacia el exterior y separado del interior, ofrece sólo algunas visiones. El tercer cuerpo es el de los científicos: es el que existe unitariamente para nuestro conocimiento, resultado del acercamiento analítico de la ciencia, que es capaz de reconstruir el todo desde las partes pero incapaz de explicar cómo el todo vivo resulta de esa mera suma, ofreciendo numerosas figuras indescifrables. Mi cuerpo, pues, el cuerpo para los otros, el cuerpo para la ciencia.

Tres cuerpos existentes acerca de los cuales, reconoce Valéry, sería interesante, aunque bastante laborioso, pensar cuáles son sus relaciones. Y el extraño método que emplea para elucidar esas relaciones es recurrir a «una fantasía»: "Digo que hay para cada uno de nosotros un Cuarto Cuerpo, que puedo llamar indiferentemente el Cuerpo Real o el Cuerpo Imaginario.» (Valéry, 1943, 930). ¿Por qué una fantasía? ¿Por qué este método tan extraño? En su «Filosofía de la danza» (1936), Valéry recordaba esa perplejidad agustiniana sobre el tiempo, conocido si no se 
piensa e incognoscible si pensamos en él, para comenzar su inquisición sobre la danza con una inquietud semejante: camino, quizás, para pensar la extrañeza de lo familiar. Avancemos que este método singular, que se revela enseguida como de una eficacia heurística extraordinaria, parte de la convicción de que no hay idea, por muy absurda que sea, aunque sea "un signo vacío», que carezca de valor para estimular al espíritu².

Evidentemente, aunque los tres cuerpos designen cosas existentes, sus relaciones no lo son, aunque no por ello son nada. La fantasía imaginada por Valéry tiene la misión de permitirnos penetrar en este espacio real pero no cósico. La relación entre los tres cuerpos no es del orden de la entidad sino lo que los estoicos llamaban lo incorporal, que incluye cuatro instancias: el espacio, el tiempo, el vacío y lo dicho o el sentido (lekton) $)^{3}$. El «cuarto cuerpo" parece ser, pues, un cuerpo incorporal. No es raro que Valéry diga que se le puede llamar indiferentemente real o imaginario, porque es las dos cosas a la vez y ninguna de ellas en particular, sino más bien la distancia inconcebible que une y separa los dos planos, de lo real-cósico y de lo imaginario-real. Para Valéry el estatuto del cuarto cuerpo es eminentemente problemático: es un cuerpo que no se separa ni se distingue, dice, del «medio desconocido e incognoscible», supuesto por los físicos como plano no perceptible que está en el origen del plano físicofenoménico; esta «idea absurda y luminosa» del cuarto cuerpo responde al «... derecho que tengo de disponer como quiera de lo inconcebible» (Valéry, 1943, 930). Está hecho de lo que los científicos ignoran; al contrario, el conocimiento «...es una producción de lo que ese Cuarto Cuerpo no es» (loc. cit.). La idea del cuarto cuerpo se dibuja sobre el fondo de dificultades o problemas planteados por los otros tres cuerpos, en parte como el problema de su misma irresolubilidad, como el elemento de lo problemático mismo: «Llamo Cuarto Cuerpo, me digo, al incognoscible objeto cuyo conocimiento resolvería de golpe todos estos problemas, porque ellos lo implican.» (op. cit., p. 931)

Ese cuerpo incorporal es «una manera de encarnación» de «alguna Inexistencia» (loc. cit.), sólo gracias a cuya suposición los problemas planteados por los otros tres cuerpos, es decir, sus relaciones incorporales, tienen «una sombra de sentido» (loc. cit.), como si ese espacio relacional e inobjetivo adquiriese algún

\footnotetext{
2 «... una idea, incluso completamente absurda, no deja de tener nunca algún valor; y una expresión, un signo vacío, no deja nunca de desgarrar el espíritu con algún aguijón.» (Valerr, 1943, 930). En la página siguiente, la idea es calificada como "absurda y luminosa" (op. cit., p. 931).

3 Véase sobre ello: BréHier (1928), Deleuze (1968) y Nancy (2001).
} 
contorno visible al proyectar sobre él esa fantasía. ¿Cuál es la consistencia de ese cuarto cuerpo, encarnación de una inexistencia, y cómo objetivarlo o al menos pensarlo?

El cuarto cuerpo de Valéry, con toda su mezcla de absurdo, de enigma y de poesía, parece cifrar el problema de pensamiento que quizás se encierra en este extrańo objeto, al mismo tiempo, tan concreto, prosaico y evidente, como es el cuerpo. Por lo pronto, parece remitir a una constitución no óntica, sustancial o natural del cuerpo: el cuerpo no es un dato o factum, sino algo fabricado o fictum. Es una producción histórica, una ficción, en el sentido inicial de que ha sido hecho y que es un efecto de determinados procesos o acontecimientos históricos. Podría decirse que lo natural mismo, el cuerpo visto como cuerpo natural, es la ficción que, desconectada del proceso de su génesis histórica, aparece como hecho o dato primario. En esta desconexión en que lo histórico aparece como natural encontramos el sentido de la ficción como ilusión y hasta como engańo: el cuerpo pretendidamente natural no sería más que una ficción en este sentido. El cuerpo-ficción es, pues, histórico, pero esto no aclara por sí solo cuál su estatus o modo de ser.

Michel de Certeau (1982), siguiendo a Foucault, ha destacado este carácter histórico y ficcional del cuerpo. El cuerpo es constituido o formado por las proyecciones de valor que un determinado grupo social realiza, el cuerpo es, en este sentido, "algo mítico», una configuración no experimental que sanciona y reglamenta unas prácticas. Cada cuerpo es, según de Certeau, «un teatro de operaciones», es decir, un escenario de las acciones que una sociedad privilegia, de manera que un cuerpo determinado se define por un sistema de opciones respecto a sus acciones, así como por un conjunto de selecciones y codificaciones referidas a dimensiones más fundamentales (límites, maneras de percibir, etc.).

El cuerpo es siempre, entonces, una realidad cultural, algo constituido a partir de un valor y sobredeterminado por él. Podría verse como el punto de equilibrio metastable (Simondon 1964) o de neutralización de fuerzas o poderes en pugna ${ }^{4}$, el punto de tensión agonística en que las fuerzas dinámicas adoptan

${ }^{4}$ Ver ANDERS (1942): «...un "valor cultural” no es más que un poder neutralizado. (...). Una vez sustraído a la lucha cotidiana, una vez neutralizado, cada fenómeno parece una "obra de arte". 
una configuración momentáneamente visible. En esa configuración se cruzan niveles de producción histórica diferentes, es decir, estratos distintos de fabricación u organización, reunidos en esa configuración incorporal que, como la de los objetos técnicos, es la de «lo inorgánico organizado» (Stiegler 1998). Para él, se cruzan niveles «organológicos» distintos, todos ellos históricos, ficticios o "protésicos» (según su terminología), todos ellos mediados o interrelacionados transductivamente (en relaciones que constituyen la especificidad de lo que ponen en relación): el del cuerpo con su organización fisiológica, el de sus órganos artificiales (técnicos, útiles, obras de arte, etc.) y el de los aparatos u organizaciones sociales, resultado de articular cuerpos y artefactos. La consideración conjunta de esos ámbitos sería el asunto complejo de una «organología general» (Stiegler 2004: 24), campo de investigación puede que más amplio que la filosofía, asimilable con la genealogía por su atención a las eventualidades que habitan lo que ha llegado a ser real, por su interés en evidenciar la génesis «diferencial» de las realidades históricas como producción de efectos sin causa (Derrida, 1968). Quizás podríamos decir que el tema de esa investigación es precisamente «el cuarto cuerpo».

En Foucault, como es sabido, esta misma investigación arqueológico-genealógica ha dado lugar a un análisis histórico-político muy radical en que se trata de llevar a cabo la eventualización de lo que para nosotros es real, con vistas a evidenciar los procesos de su constitución histórica, podríamos decir ficcional, procesos en los que «lo que no existe», como la locura, la sexualidad, etc., da lugar a lo real, como la enfermedad mental, el dispositivo actual de sexualidad, etc., que sin embargo, en sentido propio, sigue sin existir: «Se trata de mostrar por qué interferencias toda una serie de prácticas (...) ha podido hacer que lo que no existe (la locura, la enfermedad, la delincuencia, la sexualidad, etc.), devenga sin embargo algo, algo que no obstante continúa sin existir.» (Foucault, 2004, 21) 5 .

La analogía que M. de Certeau hace entre el cuerpo y la lengua aclara quizás en qué medida un «objeto evanescente», incognoscible pero codificado, da lugar a representaciones sustitutas, simulacros o ficciones (en su sentido etimológico),

Nos ponemos a gozar de lo que no tenemos el derecho a combatir.»

5 Sobre la eventualización, ver la conferencia de 1978 «Qu'est-ce que la critique? (Critique et Aufklärung)», en español en M. Foucault, Sobre la ilustración, Madrid, Tecnos, 2007. 
que fijan esa evanescencia, haciendo de ella algo real y tangible ${ }^{6}$. Pero los cuerpos son a la vez la fijación de la evanescencia y, como las lenguas, también y fundamentalmente la actividad configuradora que la evanescencia misma encierra y que permite su recreación o retroproyección abierta. En el caso de la lengua, es precisamente este aspecto el que parece destacar cuando se atiende al primado de la historia con respecto al sistema. La reinterpretación que, por ejemplo, el lingüista alemán de origen rumano, Eugen Coseriu, ha hecho de la oposición saussuriana entre sincronía y diacronía, permite avanzar en esa dirección. A partir de la idea humboldtiana de que la lengua es energeia y no ergon, es decir, actividad y no producto acabado, Coseriu $(1957,1980)$ cuestiona la oposición simple entre sincronía/diacronía y la consideración de la esencia sincrónica de la lengua, que entiende esa esencia como sistema en el sentido estricto, es decir estático, tal como ha sido defendida por Saussure, Hjelmslev o Malmberg.

Para Saussure, la lengua sólo puede ser aprehendida como realidad en cuanto sistema estático, razón por la cual para el hablante sólo ese estado es real, siendo algo inexistente la sucesión en el tiempo y lo que ha producido ese estado: «La primera cosa que sorprende cuando estudiamos los hechos de la lengua es que para el sujeto hablante su sucesión en el tiempo es inexistente: está ante un estado. También el lingüista que quiere comprender este estado, debe hacer tabla rasa

6 «... cada sociedad tiene su cuerpo, igual que su lengua, constituida por un sistema más o menos refinado de opciones entre un conjunto innumerable de posibilidades fonéticas, léxicas y sintácticas. Al igual que una lengua, este cuerpo está sometido a una administración social. Obedece a reglas, rituales de interacción y escenificaciones cotidianas. Tiene igualmente sus desbordamientos relativos a estas reglas. Como la lengua, el cuerpo es usado unas veces por los conformistas, otras veces por los poetas. Incluye, pues, mil variantes e improvisaciones en el interior del marco particular que comparaba yo con un teatro de operaciones. El conjunto a la vez codificado y móvil que forma este cuerpo no se puede aprehender, y sucede lo mismo con la lengua. Uno capta realizaciones particulares, que serían los equivalentes de frases o de estereotipos: comportamientos, acciones, ritos. Sin embargo, el campo de posibilidades y prohibiciones que el cuerpo constituye en cada sociedad no puede representarse. La multiplicidad misma de estas determinaciones sociohistóricas lo convierte en un objeto evanescente. Este cuerpo, tan estrechamente controlado, es paradójicamente la zona opaca y la referencia invisible de la sociedad que lo especifica... Ésta se consagra a codificarlo sin poder conocerlo. (...) De este cuerpo huidizo y diseminado, si bien reglamentado, cada grupo tiene necesidad de tener marcas e imágenes que posean un valor topográfico y canónico. Son representaciones sustitutas, "ficciones" de cuerpos, si restituimos al término "ficción" el sentido de producción. Estos sucedáneos tienen la doble función de representar el cuerpo por medio de citas (extractos representativos) y de fijarlo según unas normas con la ayuda de modelos. Tienen una función análoga a la de los "ejemplos" que, en una gramática, proporcionan asimismo representaciones fragmentarias de la lengua y modelos para su uso correcto. (...) Estos simulacros corporales exorcizan la perturbadora incógnita del cuerpo y le reemplazan con imágenes una objetivación ficticia...» (loc. cit.). 
con todo lo que lo ha producido e ignorar la diacronía.» (Saussure, 1916, 120, citado en Coseriu, 1980, 58). Curiosamente, esta invisibilidad para el hablante de la diacronía parece muy próxima a la invisibilidad del cuarto cuerpo, incorporal, de la que hablábamos antes. Es el punto en que la analogía entre la lengua y el cuerpo se revela más precisa: la lengua, igual que el cuerpo, no cesa de ser creada; podría decirse que tanto la lengua como el cuerpo son creación, que su ser es ser-creación ${ }^{7}$. Esto, que es invisible, es su realidad más plena. El cambio lingüístico o la génesis histórica del cuerpo no se producen en otro lugar distinto al de la lengua o el cuerpo, sea en el habla o discurso (la parole, como realización concreta de la langue) o en las realizaciones accidentales del cuerpo (en los cuerpos históricamente modificados, interpretados, etc.), como si éstas fueran realidades separables o autónomas, aunque inesenciales. Tanto el hablar concreto como los cuerpos singulares son, además de realizaciones circunstanciales, creaciones y ampliaciones de sí mismos en los que transita la lengua o la corporalidad. Como señala Coseriu, el funcionamiento y el cambio lingüísticos coinciden: la actividad y la creación son la misma cosa, «el ser de una lengua es cada vez el resultado de su devenir» (op. cit., p. 66). De ahí que para Coseriu, las lenguas sean siempre técnicas determinadas y condicionadas históricamente, «técnicas históricas del lenguaje» (Coseriu, 1966, 16).

En analogía con la interpretación humboldtiana de la lengua como actividad (Tätigkeit, energeia) y no como obra o producto inerte (Werk, ergon) ${ }^{8}$, el cuerpo habría que verlo como una actividad libre y creadora. La lengua y el cuerpo no han de ser considerados como cosas que estuvieran ante nosotros, sino como procesos abiertos y autotélicos, que tienen su fin en la propia actividad sin culminación. Como Coseriu ha señalado en relación con la lengua, se trata de la actividad «...cuyo objeto es necesariamente infinito» $(1966,21)$. El cuerpo, como la lengua, sería una «técnica histórica abierta» $(1980,63)$ o infinita que incluye la posibilidad de su propia transformación, por lo que el cambio más que ser analizado en términos retrospectivos o causales (por qué ocurre), ha de serlo, como señala Coseriu a propósito de la lengua, en términos prospectivos (cómo

\footnotetext{
7 Coseriu (1980, 71): «La lengua es (ontológicamente) creación».

8 "La lengua misma no es una obra (ergon) sino una actividad (energeia). Por eso su verdadera definición no puede ser sino genética.» (von Humboldt, 1836, 65).
} 
acontece o sobreviene) o de génesis histórica, es decir, en términos, como antes veíamos, de venida o efectuación de lo que no tiene causa determinable.

\section{5}

Cuerpo y lengua no son objetos naturales sino culturales, decíamos antes. Citemos de nuevo a Coseriu: «Ella [la lengua] no es — como a veces se piensaun objeto natural, con respecto al cual se puede distinguir entre el ser y el devenir, sino que es un objeto cultural, es decir, una producción cultural, de suerte que el devenir pertenece a su ser.» $(1980,71)$. En el lenguaje de Humboldt y de la filosofía especulativa, habría que decir que lengua y cuerpo son entidades espirituales, es decir, entidades definidas por la actividad y como actividad'. Pero lo importante aquí es que la actividad espiritual se caracteriza, además, por referirse a sí misma o autoafectarse a través de sus exteriorizaciones o productos, ya que el espíritu es, como afirma la limpia fórmula del Prólogo de la Fenomenología del espiritu, "la reflexión en el ser otro en sí mismo» (die Reflexion im Anderssein in sich selbst) (trad. Gaos, F.C.E., p. 16). Cuerpo y lengua, como entidades espirituales, están consigo cuando están fuera de sí, cuando se alienan o exteriorizan en instancias particulares, como ocurre en las obras de arte en las que es espíritu se comprende y aprehende a sí mismo como lo otro de sí $^{10}$.

Existiendo en un espacio que media o inter-media interior y exterior, que podríamos llamar «transicional» (Winnicott, 1951), los objetos culturales son maneras de proyección de idealidades que tienen la misión de hacer posible la constitución histórica de la experiencia a través de la apropiación de esa instan-

9 Sólo dos citas, de Humboldt y de Hegel: «Calificar las lenguas de trabajo del espíritu es una manera de expresarse totalmente correcta y adecuada, entre otras cosas por el hecho de que la existencia del espíritu en general sólo puede ser pensada en actividad y como actividad.» (von Humboldt, 1836, 65). "Cuando el espíritu tiende a su centro, tiende a perfeccionar su libertad; (...). La actividad es su esencia; es su propio producto; (...). Su libertad no consiste en un ser inmóvil, sino en una continua negación de lo que amenaza anular la libertad. Producirse, hacerse objeto de sí mismo, saber de sí, es la tarea del espíritu. De este modo el espíritu existe para sí mismo. Las cosas naturales no existen para sí mismas; por eso no son libres.» (Hegel, 1837, 62-63).

10 «... el poder del espíritu pensante está en que, no sólo se aprehende a sí mismo en su forma peculiar como pensamiento, sino que, además, se reconoce a sí mismo en su exteriorización a través de la sensación y la sensibilidad, se comprende en lo otro de sí mismo, en cuanto transforma en pensamiento lo alienado y con ello lo conduce de nuevo hacia sí. En esta ocupación con lo otro de sí, el espíritu pensante no es infiel a sí mismo...» (Hegel, 1845, 18). 
cia exterior y de su adopción en el ámbito de la interioridad. En el ámbito del desarrollo psicológico, en el que D. Winnicott planteó su teoría, los «objetos transicionales» tienen un papel crucial porque permiten al bebé transitar desde un estado en que se encuentra fusionado con su madre a otro en que se relaciona con ella como algo exterior, situada a una distancia que es, en cuanto tal, la forma de su unión con ella; papel crucial no sólo para el desarrollo de la identidad personal en el niño sino para la posibilitación del espacio cultural posteriormente, una vez que esos objetos han sido descargados de la ilusión inicial proyectada en ellos, una vez que pierden significación y entregan su función transicional al amplio espacio intermedio de la cultura. El «espacio transicional» en que se constituye la experiencia individual y social es un espacio de proyección de ilusiones, sólo gracias al cual el medio externo se vuelve confiable y existe para nosotros una realidad digna de crédito y abierta a la novedad; sólo entonces, dice Winnicott, se empieza «.... sentir que la vida es real, a encontrarla digna de ser vivida.» (1967: 86). El objeto transicional infantil es «la primera posesión noyo", ubicada a distancia, en una exterioridad que, sin embargo, tiene la función de unir lo que está separado, el bebé y su madre, permitiendo de este modo la constitución de un espacio autónomo y creativo de experiencia en el nińo, en el que, como decíamos antes, la realidad es digna de crédito y la vida se hace digna de ser vivida. Las experiencias o fenómenos transicionales tienen además de particular que son experiencias o actividades «no culminatorias», es decir, que no están orientadas al fin de obtener una satisfacción por la consunción del objeto sino al único fin de seguir gozando de la propia actividad. Son actividades cuyo ejemplo prototípico es el juego ${ }^{11}$.

Evidentemente, los prestigios que el nińo concede al objeto transicional, y que el adulto tolera, no son reales, son una proyección ficcional que sin embargo se revela crucial para la constitución de la realidad. Cuando este proceso es intervenido o controlado por instancias ajenas, se produce simplemente una patología o, al menos, una alienación de la experiencia en la que ésta se convierte en salida sin retorno a la exterioridad, en una simple heteronomía: «En casos de fracaso

11 «Los objetos y fenómenos transicionales pertenecen al reino de la ilusión que constituye la base de iniciación de la experiencia. Esa primera etapa del desarrollo es posibilitada por la capacidad especial de la madre para adaptarse a las necesidades de su hijo, con lo cual le permite forjarse la ilusión de que lo que él cree existe en la realidad. La zona intermedia de experiencia, no discutida respecto de su pertenencia a una realidad interna o exterior (compartida), constituye la mayor parte de la experiencia del bebé, y se conserva a lo largo de toda la vida en las intensas experiencias que corresponden a las artes y a la religión, a la vida imaginativa y a la labor científica creadora.» (WinNicotT, 1951, 22). 
prematuro en lo que respecta a la confiabilidad ambiental existe otro peligro, a saber, que ese espacio potencial sea colmado por lo que inyecta en él alguien que no es el bebé. Parece ser que todo lo que en ese espacio proviene de algún otro es material persecutorio, y el bebé no cuenta con medios para rechazarlo.» (Winnicott, 1967, 89).

Recientemente, Bernard Stiegler (2011) ha partido de estos presupuestos teóricos para analizar la actual patología consistente en la pérdida masiva del espacio transicional, con la consiguiente desafección con respecto a la realidad, su empobrecimiento al reducirse a un medio de satisfacción de pulsiones consumistas: proletarización de la misma existencia, estupidez sistémica. No es el momento de entrar a discutir esos análisis pero sí interesa en este punto destacar de ellos cómo los objetos culturales son modos de infinitud, «consistencias» (2011, 123-5), dicho con la terminología deleuziana, es decir, entidades inexistentes, de naturaleza problemática y problematizante, que tienen, sin embargo, como estamos viendo, un papel constituyente de realidad. Son los objetos del deseo, la e-moción de la razón pensante: la «cosa-misma» del pensamiento es siempre un objeto infinito inexistente ${ }^{12}$. El análisis de Stiegler pretende estudiar las condiciones tecnológicas de la proyección de esas infinitudes, porque es ahí donde está la causa de las patologías que nos aquejan en la actualidad: las tecnologías del espíritu están en manos de industrias que no tienen ningún interés porque éstas hagan su función constituyente de la experiencia; el espacio transicional, tomado por el capitalismo hiperindustrial convertido en psicopoder, se reduce a un saturado espacio de consumo adictivo. Cegada la proyección del objeto infinito, cae también la singularidad; desaparecida la creencia en el mundo, se paraliza también el elemento diferencial de apertura al cambio permanente que lo animaba.

$\mathrm{El}$ «cuarto cuerpo» designa una entidad que es objeto, no de la percepción, ni del conocimiento intelectual, sino del pensamiento (según la conocida distinción kantiana). Es un cuerpo-problema. Ha de ser incorporal porque es una consistencia, algo que, como veía Valéry, no existe o, en todo caso, encarna fantasmáticamente una inexistencia. Al igual que la lengua no es una nomenclatura para cosas que serían conocidas antes por otra vía, sino la posibilidad misma de que haya

12 En este punto me permito remitir a DE LA Higuera (2013). 
cosas al crear su ser-esta-o-aquella-cosa ${ }^{13}$, el cuerpo-problema, el cuerpo-mismo es también un hecho trascendental cuyo concepto no es el resultado de representar una realidad positiva sino el resultado de una construcción especulativa. Si nuestro abordaje del problema del cuerpo es realmente filosófico, esto no debe extrañarnos: la filosofía ha de construir conceptualmente su propio objeto porque éste nunca es una cosa determinada del mundo, ni siquiera lo es el cuerpo como problema filosófico. La construcción especulativa del concepto de cuerpo es el cometido de una ontología del cuerpo. Es el asunto al que parecían entregarse las divagaciones de Valéry sobre «el cuarto cuerpo». Es, además, el motivo por el que pensar en el cuerpo causa esa perplejidad que sin embargo no tenemos habitualmente cuando nos limitamos a vivirlo. Se trata de la perplejidad (thaumas) que está, como ya sabía Platón, en el origen de la filosofía y que es la actitud ontológica misma.

Evidentemente nuestra ontología del cuerpo no pretende restaurar la metafísica en su sentido tradicional. Se trata en todo caso de una ontología histórica que no tiene por objeto el ser como entidad, sino el «ser singular plural» (Nancy, 1996), es decir, un ser que es lo mismo que el existir de los existentes, infinitamente localizado en el espacio relacional o intersticial (un espacio vacío) en que los existentes se exponen unos a otros. La perplejidad ontológica es no sólo el signo del desaprendizaje a que nos vemos obligados cuando intentamos pensar la cosa misma, atravesada de nada, sino también el efecto que nos causa tener para ello que recurrir a falacias metafísicas, concebidas originalmente para pensar con intención representativa o cognoscitiva un ser pleno de realidad ultrarreal, de cuya naturaleza ficticia somos ahora conscientes; falacias que ahora sabemos que lo son pero que, como Arendt vio a la perfección, son el único lugar donde hay testimonio del plano ontológico del pensamiento y de donde se pueden rescatar quizás algunos rescoldos que aún puedan ser reavivados ${ }^{14}$. Razón por la que ninguna filosofía, ni siquiera la del cuerpo, menos aún que la que trate de otros asuntos en principio más abstractos o filosóficos, puede pretender ingenuamente ser antimetafísica (todos los empirismos, naturalismos, biologicismos, mentalismos, antropologismos, etc.).

No obstante, probablemente Foucault tiene razón cuando descubre, junto a la vivencia común del cuerpo-cosa, ligado siempre a un aquí y a un ahora, una experiencia no-cósica, tan primaria como ésta, experiencia del «cuerpo utópico» (Foucault, 1967), que bien pudiera ser en algún sentido una experiencia metafí-

\footnotetext{
13 Ver Coseriu (1999, 52).

14 Ver Arendt (1971).
} 
sica original, más inmediata que la experiencia hermenéutica que podemos hacer con el texto de la clausurada metafísica. Bien pudiera tratarse del testimonio singular de la «desclausura» (déclosion) (Nancy, 2005) que, desde el inicio, la clausura metafísica encierra y libera al mismo tiempo.

En esta conferencia radiofónica de 1966, «Le corps utopique», aborda Foucault la contraposición entre dos experiencias del cuerpo igualmente posibles y reales, la tópica y la utópica, aunque esta última más radical que la primera: por un lado, la experiencia de mi cuerpo como siempre aquí, pesado, real como una cosa, cuerpo que es lo contrario de una utopía (quizás las utopías han nacido precisamente contra ese cuerpo, para anularlo o hacerlo desaparecer, apunta Foucault); por otro lado, la experiencia de un cuerpo que, por sus opacidades, sus extrańezas, sus fantasmas, es más vida que cosa («nada es menos cosa que él»), dispuesto a volatilizarse en cualquier momento. Este segundo cuerpo posee «lugares sin lugar», es algo que "...está siempre en otro lugar, está ligado siempre a todos los otros lugares del mundo y, a decir verdad, está en otro lugar distinto al mundo» (Foucault 1967, 3-4). Cuerpo, entonces, que es «el actor principal de todas las utopías» (ibid., p. 3), de modo que para pensar en una utopía basta remitirse, dice, a esta «experiencia profunda y originariamente utópica del cuerpo» (ibid., p. 4).

Este cuerpo utópico, "punto cero del mundo», como lo llama Foucault, su corazón vacío, lugar sin lugar que irradia sin embargo todos los lugares, está en cada uno de nosotros o, mejor, nosotros en él, junto con la infinidad de existentes, y formando ese nosotros de exposición que es el mundo. Siendo el cuerpo lugar singular-plural de existencia, en él se componen todas las formas de desubicación, de insustancialidad y de exposición, que son propias de ella: el estar en ningún lugar (u-topía), fuera de lugar (a-topía), en lo otro del lugar (hetero-topía) ${ }^{15}$, en el afuera de la constante salida fuera de sí (ec-topía), etc. Este es el cuerpo del ser, una vez que el ser ya no designa nada, es decir, ningún ente sustancial o suprasustancial sino sólo el existir de los existentes. Y es un cuerpo sin ser, una vez que ya el cuerpo no saca su potencia más que de la nada que encierra (y por eso puede ser un cuerpo político).

Eso es lo que para nosotros se hace pensable como cuerpo: «el cuerpo es el ser-expuesto del ser» (Nancy, 2000, 32), la salida infinita de sí de un ser que sólo

15 A estos «espacios otros» dedicó otra bella conferencia Foucault en 1967: «Des espaces autres. Hétérotopies», aunque publicada en 1984. 
es localidad, que es el ser que-es, ser-ente (y no el ser del ente) (Nancy, 2010, 67), que existe de modo finito y singular en un único lugar vacío multiplicado infinidad de veces como espaciamiento. El cuerpo es el ser que transita en los entes reales haciéndolos ser sin originarlos ni fundarlos, efectuación de lo que no tiene causa ni deriva de ningún dato. Es la venida a la presencia de lo que no es nada, que viene de ninguna parte para ir a ningún sitio: lugar absoluto de la existencia, finitud irreparable del infinito.

El cuerpo, por tanto, es pensable como la apertura de la existencia finita al infinito, la tangibilidad de lo que sólo existe en el afuera y en salida permanente. Su cifra, condensada plásticamente, la ha visto J.-L. Nancy en el motivo bíblico y pictórico del noli me tangere en su libro de 2003, con ese título. El pensamiento del cuerpo es también la posibilidad actual de su resurrección: no un retorno a la vida, sino la sublevación o insurrección ante la muerte, el surgimiento de una verticalidad perpendicular a la tumba horizontal, un «tenerse en pie ante y en la muerte», que es la verdad infinita de una vida mortal y singular, verdad inconmensurable con el plano horizontal de una finitud muerta ${ }^{16}$. Se trata de un cuerpo resucitado o insurrecto, que hay que poner en el centro del problema del sujeto político.

Pero, aunque sea eminentemente política, la ontología del cuerpo se revela como la ontología general. En la actualidad, toda ontología lo sería del cuerpo. Es probablemente el resultado de la opción por un materialismo radical, «materialismo incorporal» (Foucault, 1971), presente en una buena parte de las corrientes filosóficas contemporáneas que no renuncian a la especificidad de la filosofía. Se trata de un materialismo que elimina todo presupuesto, sustancialidad o sustrato y que, por tanto, se abre a una eleuterología u ontología de la «libertad material», de la materia libre, cuyo objeto lo constituirían encarnaciones de cosas inexistentes, como el «cuarto cuerpo» de Valéry ${ }^{17}$.

16 «...la anastasis, la "resurrección”, es decir, la elevación o sublevación (“insurrección” es también un sentido posible del término griego). Ni regeneración, ni reanimación, ni palingenesia, ni renacimiento, ni reviviscencia, ni reencarnación: sino la sublevación, sino el levantamiento o bien el levantarse en tanto que verticalidad perpendicular a la horizontalidad de la tumba — no abandonándola, no reduciéndola a nada, sino afirmando en ella la disposición jtambién, pues, la reserva! de un intocable, de un inaccesible. (...) No dialectiza ni mediatiza la muerte: hace elevarse allí la verdad de una vida, de toda vida en tanto que mortal y de cada vida en tanto que singular. Verdad vertical, inconmensurable al orden horizontal en el que la vida muerta se resuelve en trozos de materia.» (NANCY, 2003, 33).

${ }^{17}$ Los trabajos de J.-L. Nancy tienen a mi juicio una especial relevancia en esta reinterpretación de la ontología existencial. Citémoslo de nuevo: «...el cuerpo da lugar a la existencia. Y 


\section{Bibliografía}

Anders, G. (1942). «Thèses sur les besoins, la culture, le besoin de culture, les valeurs culturelles, les valeurs», en http://www.geocities.com/nemensisite/besoin.anders. htm

Arendt, H. (1971). «Introducción» a La vida del espiritu, Barcelona: Paidós, 2002.

Brehier, E. (1928). La théorie des incorporels dans l'ancien stoücisme, Paris: Vrin.

Coseriu, E. (1957). "Sincronía, diacronía e historia», en Sincronía, diacronía e historia, Madrid: Gredos, 1973.

- (1966). «El hombre y su lenguaje», en El hombre y su lenguaje, Madrid: Gredos, 1977.

— (1980). «Du primat de l'histoire», en Energeia (Tübingen), n. ${ }^{2}$ 2, 2010: 56-72.

- (1999). «Diez tesis a propósito de la esencia del lenguaje y del significado», en Energeia, IV (2012): 49-52.

De Certeau, M. (1982). «Historias de cuerpos» (entrevista con Vigarello), en Historia y grafía, UIA, México, julio-diciembre 1997 (on line en http://estafeta-gabrielpulecio.blogspot.de/2010/07/michel-de-certeau-historias-de-cuerpos.html).

De la Higuera, J. (2013). "La filosofía y el filosofar», en La filosofía y su otro. Para pensar el presente, Granada: Editorial Universidad de Granada.

De Saussure, F. (1916). Cours de linguistique générale, Lausanne/Paris.

Deleuze, G. (1968). Logique du sens, Paris: Minuit, 1968.

Derrida, J. (1968). «La différance», en Théorie d'ensemble. Tel Quel. Choix, Paris: Seuil.

Foucault, M. (1967). «Le corps utopique» (Conferencia radiofónica en France-Culture, 1966), en http://lesilencequiparle.unblog.fr/2009/11/23/le-corps-utopiquemichel-foucault-pas-de-deux-norman-mclaren/

- (1971). L'ordre du discours, Paris: Gallimard.

- (1984). «Des espaces autres. Hétérotopies», en Dits et écrits, Paris: Gallimard, vol. IV.

muy precisamente, él da lugar a esto, que la existencia tiene como esencia no tener en absoluto esencia. Por ello, la ontología del cuerpo es la ontología misma: el ser no es allí nada previo o subyacente al fenómeno. El cuerpo es el ser de la existencia. (...) El cuerpo ontológico no es todavía pensado. La ontología no es todavía pensada en tanto que fundamentalmente es una ontología del cuerpo = del lugar de existencia, o de la existencia local.» (Nancy 2000: 16-7). La idea de «libertad material» se puede hallar en esta misma obra en las pp. 33-4. Sobre la eleuterología en general, véase Nancy (1988). 
- (1990). "Qu'est-ce que la critique? (Critique et Aufklärung)». Bulletin de la Société Française de Philosophie, n. ${ }^{\circ}$ 84, 35-63.

- (2004). «Leçon du 10 janvier 1979», en Naissance de la biopolitique. Cours au Collège de France 1978-9, Paris: Hautes Études/Gallimard/Seuil.

Hegel, G. W. F. (1837). Lecciones sobre la filosofia de la historia universal, Madrid: Alianza Editorial, 1980 (trad. Gaos).

- (1845). Lecciones de estética, vol. I. Barcelona: Península, 1989 (trad. de R. Gabás).

Nancy, J.-L. (1988). L'expérience de la liberté, Paris: Galilée.

- (1996). Etre singulier pluriel, Paris: Galilée.

— (2000). Corpus, Paris: Métailié.

- (2001). Le «Il y a» du rapport sexuel, Paris: Galilée.

- (2003). Noli me tangere. Essai sur la levée du corps, Paris: Bayard.

- (2005). La déclosion. Déconstruction du christianisme 1, Paris: Galilée.

- (2010). «La différance, ici et maintenant», en Magazine Littéraire, n. ${ }^{\circ} 498$, 66-8.

Simondon, G. (1964). Lindividuation psychique et collective, Paris: Aubier, 2007.

Stiegler, B. (1998). «Leroi-Gourhan: L'inorganique organisé», en Cahiers de médiologie, 2. ${ }^{\circ} 1998$, 187-194 (on line en http://mediologie.org/cahiers-de-mediologie/06_mediologues/stiegler.pdf).

- (2004). De la misère symbolique 1. L'epoche hiperindustrielle, Paris: Galilée.

- (2011). Ce qui fait que la vie vaut la peine d'être vécue: De la pharmacologie, Paris: Flammarion.

Valerr, P. (1936). «Philosophie de la danse», en CEuvres, I, Paris: Gallimard, 1957, 1390-1403.

— (1943). «Réflexions simples sur le corps», en CEuvres, I, op. cit., 923-931.

Von Humboldt, W. (1836). Sobre la diversidad de la estructura del lenguaje humano y su influencia sobre el desarrollo espiritual de la humanidad, Madrid: Anthropos, 1990 (trad. de A. Agud).

Winnicott, D. W. (1951). «Objetos transicionales y fenómenos transicionales», en Realidad y juego, Barcelona: Gedisa, 2008.

- (1967). «La ubicación de la experiencia cultural», en Realidad y juego, op. cit.

Recibido: 28/10/2013

Aceptado: 18/12/2013 